\title{
(2) OPEN ACCESS \\ Multiple myeloma-derived exosomes inhibit osteoblastic differentiation and improve IL-6 secretion of BMSCs from multiple myeloma
}

\author{
Zhaoyun Liu @ , Hui Liu, Yanqi Li, Qin Shao, Jin Chen, Jia Song, Rong Fu
}

Hematology department, Tianjin Medical University General Hospital, Tianjin, China

Correspondence to Professor Rong Fu, Tianjin Medical University General Hospital, Tianjin 300052, China; florai@sina.com

Accepted 27 May 2019 Published Online First 28 November 2019

\section{Check for updates}

(C) American Federation for Medical Research 2020. Re-use permitted under CC BY-NC. No commercial re-use. Published by BMJ.

To cite: Liu Z, Liu H, Li Y, et al. J Investig Med 2020;68:45-51.

\begin{abstract}
Bone marrow stromal cells (BMSCs) play a critical role in multiple myeloma (MM) pathogenesis by cell contact, and secretion of cytokines, growth factors and extracellular vesicles. Exosomes are secreted by almost all cell types and are recently reported to mediate local cell-to-cell cross-talk by transferring messenger RNAs, LncRNAs, and proteins. Compelling studies have identified BMSCderived exosomes induce proliferation, migration, survival, and drug resistance of MM cells. However, whether MM cell-derived exosome also plays a role in function in BMSC remains unclear. Here we investigated the effect of MM cell-derived exosomes on the interleukin (IL)-6 secretion and osteoblastic differentiation capability of BMSC from patients with MM. Furthermore we investigated the IL-6 secretion relative regulation protein APE1 and NF$\mathrm{KB}$ and osteoblastic differentiation protein Runx2 (runt-related gene 2), Osterix and osteocalcin (OCN). Our results showed that MM cell-derived exosomes promoted IL-6 secretion and suppressed osteoblastic differentiation and mineralization of BMSCs. Mechanistically, we demonstrated that MM cellderived exosomes lead to an increase in APE1 and $\mathrm{NF}-\mathrm{kB}$ and a reduction in Runx2, Osterix and $\mathrm{OCN}$ in BMSCs. Taken together, MM cell-derived exosomes induce the secretion of IL-6 and poor osteoblastic differentiation of BMSCs.
\end{abstract}

\section{INTRODUCTION}

Multiple myeloma (MM) is a common and life-threatening hematologic malignancy. Bone disease is a defining characteristic of MM and the major cause of morbidity. It manifests as lytic lesions or osteopenia and is often associated with severe pain, pathologic fracture, spinal cord compression, vertebral collapse, and hypercalcemia. Bone marrow microenvironment disorder is an important pathologic mechanism. The cross-talk between myeloma cells and bone marrow mesenchymal stem cells, which could lead to the disorder, activates various signaling pathways and cytokines such as interleukin (IL)-6, and other secretions, and then promotes the growth, migration, and drug resistance of MM cells. The interplay could be divided in two ways: direct action and indirect action. Direct action refers

\section{Significance of this study}

What is already known about this subject?

- Multiple myeloma (MM) exosomes enhanced osteoclast activity and also blocked osteoblast differentiation, leading to a reduction in Runx2 (runtrelated gene 2), Osterix and collagen $1 \mathrm{~A} 1$ in osteoblasts in 5TGM1 murine model.

- MM cells activate the NF-kB signaling pathway by directly adhering to bone marrow stromal cells (BMSCs) and release interleukin (IL)-6 which can promote proliferation and migration of MM cells.

- Osterix may act as downstream of Runx2 during osteoblast differentiation.

What are the new findings?

- MM cell-derived exosomes promoted IL-6 secretion of BMSCs from patients with MM.

- MM cell-derived exosomes suppressed osteoblastic differentiation and mineralization of BMSCs from patients with MM.

- MM cell-derived exosomes regulate IL-6 secretion relative protein APE1 and NF-kB and osteoblastic differentiation protein Runx2, Osterix and osteocalcin of BMSCs from patients with MM.

How might these results change the focus of research or clinical practice?

- The exosome may be a communicator in the cross-talk between MM and BMSCs and may be a potential target for patients with MM.

to MM cells activating the NF-kB signaling pathway by directly adhering to bone marrow stromal cells (BMSCs) and releasing IL-6, which can promote proliferation and migration of MM cell, ${ }^{1}$ while it can also boost B cell activating factor and activin $\mathrm{A}^{2-4}$ to promote the proliferation of $\mathrm{MM}$ cells. These actions can affect the balance between osteoblast and osteoclast and then result in multiple myeloma bone disease (MBD). Indirect action refers to the 'communication' between MM cells and BMSCs mediated by cytokines such as IL-6, IGF-1 and exosomes. Here, we focused on the 
effects of exosomes derived from MM cells on the indirect action between MM cells and BMSCs.

Exosomes $(40-100 \mathrm{~nm})$ are extracellular vesicles that contain a specific composition of proteins, lipids, RNA, and DNA that mediate cell-to-cell communication through the horizontal delivery of bioactive molecules. ${ }^{5}$ Recent studies have reported that exosomes derived from cancer cells may influence survival, apoptosis, invasion, angiogenesis and resistance to chemotherapy. ${ }^{6-9}$ Low expression of miR-15a could promote MM cell proliferation, which also can be induced by inhibiting the expression of proapoptotic gene caspase 3 and apoptosis inhibiting gene BCL-2. ${ }^{10}{ }^{11}$ Additionally, it has been reported that BMSC-derived exosomes also are involved in the activation of several survival relevant pathways, including c-Jun $\mathrm{N}$-terminal kinase, p38, p53, and Akt, and induced drug resistance of MM cells as well. Taken together, it demonstrates involvement of exosome-mediated communication in BMSC-induced proliferation, migration, survival, and drug resistance to $\mathrm{MM}$ cells. In the MM cell-derived exosomes, the level of miR-135 $\mathrm{b}^{12}$ is highly expressed and is also enriched in CD147, zinc finger protein 224, CD44 and other proteins. It activates mitogen-activated protein kinase (mTOR-MAPK) and NF-kB cell signaling pathways of the endothelial cell, thereby promoting angiogenesis and tumor cell growth. ${ }^{13}{ }^{14}$ However, the effect of MM cellderived exosomes on BMSCs has not been reported.

The main pathogenesis of MBD is the imbalance between osteoblasts and osteoclasts. Varieties of cytokines such as chemokine macrophage inflammatory protein 1 alpha (MIP$1),{ }^{15}$ cysteine-rich protein 61 (CYR61) $)^{16}$ and complement ${ }^{17}$ are involved in osteoblasts function inhibition and osteoclast activity enhancement, and finally result in abnormal serum bone biochemical markers ${ }^{18}$ and imaging change at the early clinical stage. The exosomes derived from MM cells can promote osteoclast function by increasing the expression of CXCR $4 .{ }^{10}$ But there is no related research that reported whether MM cell-derived exosomes could influence osteoblastic differentiation of BMSCs from patients with MM.

In our study, we hypothesized that MM cell-derived exosomes might contribute to the secretion of IL-6 and osteoblastic differentiation. MM cell-derived exosomes were isolated and characterized in vitro. Then we conducted MM cell-derived exosomes into BMSCs to test cytokine secretion and osteoblast differentiation ability. Furthermore we investigated the IL- 6 secretion relative regulation protein apyrimidic eEndonuclease 1(APE1) and nmuclear factor $\mathrm{kB}(\mathrm{NF}-\mathrm{kB})$ and osteoblastic differentiation protein Runx2 (runt-related gene 2), Osterix and osteocalcin (OCN). Our findings provide an evidence that MM cellderived exosomes may induce the secretion of IL- 6 and inhibit osteoblastic differentiation of BMSCs.

\section{MATERIALS AND METHODS Patients and cells isolation Study subjects}

The study included 27 newly diagnosed patients with MM (19 men and 8 women) at the Tianjin Medical University General Hospital (Tianjin, China) from January 2017 to December 2017 according to the International Myeloma

\begin{tabular}{ll}
\hline $\begin{array}{l}\text { Table } 1 \\
\text { study }\end{array}$ & Characteristics of patients with MM in the current \\
\hline Total number of patients & 27 \\
\hline Gender & 19 male, 8 female \\
\hline Age, median (range) & $63(45-82)$ \\
Type of MM & $\begin{array}{l}\text { IgG (17), IgA (5), light- } \\
\text { chain (5) }\end{array}$ \\
\hline Stage at diagnosis (International Staging System, & \\
ISS) & \\
\hline I & $2(8 \%)$ \\
\hline II & $6(22 \%)$ \\
\hline III & $19(70 \%)$ \\
\hline Bone disease & $11(41 \%)$ \\
\hline Stage A & $16(59 \%)$ \\
\hline Stage B/C & $17(63 \%)$ \\
\hline Parameters at baseline & $10(37 \%)$ \\
\hline Creatinine clearance $>30 \mathrm{~mL} / \mathrm{min}$ & $8(30 \%)$ \\
\hline Creatinine clearance $\leq 30 \mathrm{~mL} / \mathrm{min}$ & $19(70 \%)$ \\
\hline Hb $\geq 100 \mathrm{~g} / \mathrm{L}$ & $5(19 \%)$ \\
\hline $\mathrm{Hb}<100 \mathrm{~g} / \mathrm{L}$ & $22(81 \%)$ \\
\hline Ca $>2.75 \mathrm{mmol} / \mathrm{L}$ & \\
\hline Ca $\leq 2.75 \mathrm{mmol} / \mathrm{L}$ &
\end{tabular}

$\mathrm{Ca}$, calcium; $\mathrm{Hb}$, hemoglobin; MM, multiple myeloma.

Working Group criteria. The characteristics of the patients are shown in table 1 . The newly diagnosed plasma cells (PCs) were purified from bone marrow samples using CD138 immunomagnetic microbeads (MidiMACS system, Miltenyi Biotec, Auburn, California), and the purity of the positively selected PCs was $>90 \%$ in all cases. Informed consent was acquired prior to study inclusion. Primary BMSCs obtained from patients with MM were cultured and selected in Dulbecco's modified Eagle/F12 medium (Gibco) supplemented with $15 \%$ fetal bovine serum (Gibco) in 6-well plates and used at the third passage.

\section{Exosome isolation}

To isolate cell-derived exosomes, myeloma cells from patients with MM and MM cell line RPMI-8226 were cultured in RPMI 1640 medium (Gibco) containing 10\% fetal bovine serum (Gibco), $100 \mu \mathrm{g} / \mathrm{mL}$ penicillin (Gibco), and $100 \mathrm{U} / \mathrm{mL}$ streptomycin (Gibco) in a humidified atmosphere $\left(37.5^{\circ} \mathrm{C}\right.$ and $\left.5 \% \mathrm{CO}_{2}\right)$ for 24 hours. To remove exosomes of fetal bovine serum used in culture media, it was subjected to ultracentrifugation at $100,000 \mathrm{~g}$ for 3 hours at $4{ }^{\circ} \mathrm{C}$. The culture medium was collected and centrifuged at $800 \mathrm{~g}$ for $5 \mathrm{~min}$, followed by $2000 \mathrm{~g}$ for $10 \mathrm{~min}$ to get rid of lifted cells. The supernatant was filtered on a $0.1 \mathrm{~mm}$ pore polyethersulfone membrane (Corning) to remove cell debris and large vesicles, and then concentrated through a $100,000 \mathrm{Mw}$ cut-off membrane (CentriPlus-70, Millipore, Bedford, Massachusetts, USA). The volume of supernatant was reduced from approximately $250-500 \mathrm{~mL}$ to less than $5 \mathrm{~mL}$. The supernatant was then ultracentrifuged at $100,000 \mathrm{~g}$ for 1 hour at $4^{\circ} \mathrm{C}$ using $70 \mathrm{Ti}$ rotor (Beckman Coulter). The resulting pellets were resuspended in $6 \mathrm{~mL}$ phosphate-buffered saline (PBS) and ultracentrifuged at $100,000 \mathrm{~g}$ for 1 hour at $4^{\circ} \mathrm{C}$ using $100 \mathrm{Ti}$ rotor (Beckman Coulter). ${ }^{19}$ 


\section{Transmission electron microscopy}

First, isolated exosomes were resuspended in PBS, and then absorbed $10 \mu \mathrm{L}$ onto Copper $(\mathrm{Cu})$ grids for $5 \mathrm{~min}$. Then, the grids were stained with $1 \%$ of uranyl acetate at room temperature for $1 \mathrm{~min}$. Transmission electron microscopy (TEM) was performed at $\times 200,000$ magnification on an H600 TEM (Hitachi, Japan). ${ }^{20}$

\section{Protein measurements}

Aliquots $(5-10 \mu \mathrm{L})$ of isolated exosomes were dispensed into wells of a 96-well plate, and the assay was performed as recommended by the manufacturer (Pierce BCA Protein Assay Kit, Thermo Scientific, Rockford, Illinois, USA). Total protein concentrations were determined using a linear standard curve established with bovine serum albumin. ${ }^{20}$

\section{Western blot analysis}

Exosomes were lysed with a lysis buffer (Cell Signaling Technology, Beverly, Massachusetts, USA) that is mixed with $5 \mathrm{mM}$ sodium fluoride $(\mathrm{NaF}), 2 \mathrm{mM} \mathrm{Na} 3 \mathrm{VO} 4,1 \mathrm{mM}$ phenylmethylsulfonyl fluoride (PMSF), $5 \mu \mathrm{g} / \mathrm{mL}$ leupeptin, and $5 \mu \mathrm{g} / \mathrm{mL}$ aprotinin. The extracted proteins $(100 \mu \mathrm{g} /$ lane) were separated by $8 \%$ sodium dodecyl sulfatepolyacrylamide gel electrophoresis (SDS-PAGE). After electrophoresis, the SDS-PAGE gels were electrophoretically transferred to polyvinylidene difluoride (PVDF) membranes (Bio-Rad Laboratories, Hercules, California, USA). Anti-CD63 (Abcam,TS63), anti-Hsp70 (Abcam, 3A3), anti-CD138 (Abcam, EPR6454), anti-Osterix (Abcam, ab94744), and OCN (Abcam, ab133612) antibodies were used. Western blot was also used to evaluate the content of Ape1 (\#4128), NF-kB (\#8242), Runx2 (\#9647) and glyceraldehyde-3-phosphate dehydrogenase (GAPDH) (\#5174) (Cell Signaling Technology) in cell extracts. Cells were lysed with a lysis buffer $(20 \mathrm{mM}$ Tris- $\mathrm{HCl}, \mathrm{pH} 8.0$, $150 \mathrm{mM} \mathrm{NaCl}, 2 \mathrm{mM}$ EDTA, $100 \mathrm{mM} \mathrm{NaF}, 1 \% \mathrm{NP}-40$, $1 \mu \mathrm{g} / \mathrm{mL}$ leupeptin, $1 \mu \mathrm{g} / \mathrm{mL}$ antipain, and $1 \mathrm{mM}$ phenylmethylsulfonyl fluoride), and the protein concentrations were examined by the BCA Protein Assay Kit (Pierce). Proteins $(30 \mu \mathrm{g})$ were separated by SDS-PAGE. After electrophoresis on an $8 \%$ SDS gel, the proteins were transferred to a PVDF membrane (Bio-Rad Laboratories). PVDF membranes were blocked with 5\% skim milk followed by overnight incubation at $4^{\circ} \mathrm{C}$ with the following antibodies: anti-p21, anti-p27, anticyclin D1, anticyclin E, anti-Runx2, anti-OCN, anti-Osterix and anti-GAPDH antibody. After washing with Tris-buffered saline with Tween-20, the membranes were incubated for 1 hour at room temperature with antirabbit $\operatorname{IgG}$ sheep antibody or antimouse $\operatorname{IgG}$ sheep antibody coupled to horseradish peroxidase (Amersham). Reactive proteins were visualized using a chemiluminescence kit (Millipore).

\section{Multiparametric flow cytometry analysis}

To fulfill the criteria of the International Society for Cellular Therapy and to exclude contamination of mesenchymal stem cell (MSC) cultures by hematopoietic cells, MSCs were analyzed by flow cytometry. Five antibodiesfluorescein isothiocyanate (FITC)-conjugated anti-CD34, PerCP-conjugated anti-CD45, allophycocyanin(APC)conjugated anti-CD105, PC7-conjugated anti-CD90, and
PE-conjugated anti-CD73 antibodies (BD Biosciences)were used to identify the MSCs. ${ }^{2122}$

\section{ELISA assay}

The levels of IL- 6 were measured by IL- 6 ELISA (Human IL-6 Immunoassay; R\&D Systems) according to the manufacturer's protocol. Anti-IL-6 neutralizing antibody and the related isotype control were purchased from R\&D Systems. The supernatant of exosome cultured with BMSCs was collected to test the level of IL-6. The absorbance was measured at $450 \mathrm{~nm}$ and $570 \mathrm{~nm}$. To avoid the influence of cell numbers on cytokines levels, data were normalized to cell counts. The assays were repeated three times. ${ }^{23}$

\section{Quantitative real-time PCR}

Total RNA was extracted using TRIzol Reagent (Invitrogen, Carlsbad, California, USA). The quality of RNA samples was determined by an ultraviolet spectrophotometer (Bio-Rad, Hercules, California, USA), and the 260:280 nm absorbance ratio between 1.8 and 2.0 was regarded as qualified. Finally, total RNA was dissolved in $20 \mu \mathrm{L}$ diethylpyrocarbonatetreated water and then was synthesized to complementary DNA according to TIANScript RT Kit manufacturer's instructions (Tiangen, Beijing, China). The levels of RNA chosen were quantified by quantitative PCR using Bio-Rad iQ5 real-time system (Bio-Rad). The levels of RNAs were determined by the $\Delta \Delta \mathrm{Ct}$ method using $\beta$-actin as a control. Quantitative PCR was subsequently performed using SYBR Premix Ex Taq II (Invitrogen) in a 96-well plate according to the manufacturer's protocol. Primer sequences are shown in table $2 .^{22}$

\section{In vitro osteogenic differentiation}

Osteogenic differentiation of BMSCs was investigated in 6-well plates with and osteogenic factors $\left(1 \times 10^{-7}\right.$ $\mathrm{mol} / \mathrm{L}$ dexamethasone, $0.05 \mathrm{~g} / \mathrm{L}$ vitamin $\mathrm{C}, 0.01 \mathrm{~mol} / \mathrm{L} \beta$-sodium glycerophosphate, $100 \mathrm{U} / \mathrm{mL}$ penicillin (Gibco), and $100 \mu \mathrm{g} / \mathrm{mL}$ streptomycin (Gibco)). In the osteogenic factor medium over a 3-week period, BMSCs were cultured with either RPMI-8226 cell-derived exosomes or blank vector. Osteogenic characteristics were identified by von Kossa and alkaline phosphatase (ALP) staining. To confirm the

\begin{tabular}{|c|c|c|}
\hline Gene & Sense and antisense sequences & bp \\
\hline \multirow{2}{*}{ Runx2 } & F: 5'-GACGAGGCAAGAGTTTCACC-3' & 106 \\
\hline & R: 5'-GGTTCCCGAGGTCCATCTAC-3' & \\
\hline \multirow[t]{2}{*}{$\mathrm{OCN}$} & F : 5'-CACTCCTCGCCCTATTGGC-3' & 112 \\
\hline & R: 5'-CCCTCCTGCTTGGACACAAAG-3' & \\
\hline \multirow[t]{2}{*}{ Osterix } & F : 5'-CCTCTGCGGGACTCAACAAC-3' & 128 \\
\hline & R : 5'-AGCCCATTAGTGCTTGTAAAGG-3' & \\
\hline \multirow[t]{2}{*}{ IL-6 } & F : 5'-ACTCACCTCTTCAGAACGAATTG-3' & 149 \\
\hline & R : 5'-CCATCTTTGGAAGGTTCAGGTTG-3' & \\
\hline \multirow{2}{*}{$\begin{array}{l}\text { Apyrimidic } \\
\text { eEndonuclease } 1 \\
\text { (APE1) }\end{array}$} & F : 5'- TTAGATTGGG TAAAGGAAGAAGC-3' & 121 \\
\hline & R : 5'- CTGACCAGTATTGATGAGAGAGT-3' & \\
\hline \multirow[t]{2}{*}{$\beta$-actin } & F : 5'-CCTGGCACCCAGCACAAT-3' & 144 \\
\hline & R : 5'-GGGCCGGACTCGTCATAC-3' & \\
\hline
\end{tabular}

bp, base pair; F, forward; IL-6, interleukin 6; OCN, osteocalcin; R, revise; Runx2, runtrelated gene 2 . 


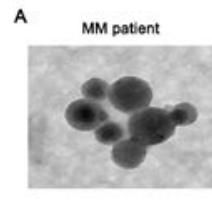

C

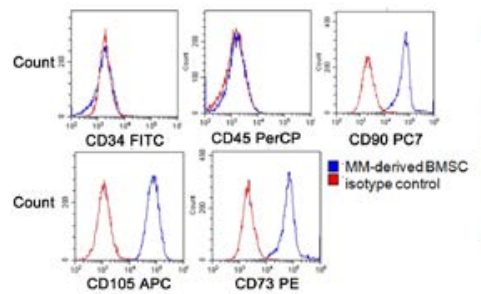

Figure 1 Characterization of exosomes derived from MM cells and MM-derived BMSCs. (A)Transmission electron microscopy image of isolated exosomes from MM cells of patients and RPMI-8226 cells. Exosomes range in size from $20 \mathrm{~nm}$ to $80 \mathrm{~nm}$. (B) Western blotting analysis of CD63, Hsp70 and CD138 in MM cells from patients with MM and RPMI-8226 cell linederived exosomes and cellular lysates. (C) Mean fluorescence intensity of CD34, CD45, CD90, CD105 and CD73 was determined on MM-derived BMSC by flow cytometric analysis. Representative histograms are shown. The red line represents the respective isotype control, and the blue line represents patients with MMderived BMSC. (D) Representative micrograph depicts morphology of patients with MM-derived BMSC. BMSC, bone marrow stromal cell; Exo, exosomes; MM, multiple myeloma;FITC,fluorescein isothiocyanate ;APC,allophycocyanin ;PE, phycoerythrin.

presence of osteoblast(OB), the ALP expression, an early osteoblast marker, is detected using the ALP staining kit (Sigma-Aldrich, Taufkirchen, Germany). ALP staining produced a deep pink color at 3 weeks in the BMSCs grown in the osteogenic factor medium. von Kossa staining was performed to confirm that the OB synthesized and mineralized the extracellular matrix. The mineralized nodules were detected in both groups after 3 weeks of culture. The number of mineralized nodules per patient was calculated and used as an index of OB function. von Kossa staining of grown cells gave rise to a dark color at 3 weeks, indicating calcium deposition. . ${ }^{24}$

\section{Statistical analysis}

Statistical Product and Service Solutions (SPSS) V.17.0 software was used for statistical analysis. The paired t-test was conducted to calculate the long non-coding RNA (LncRNAs) levels between MM cells and MM cell-derived exosomes. PCR and IL- 6 level data results were done by Student's t-test. A value of $\mathrm{p}<0.05$ was considered statistically significant.

\section{RESULTS}

\section{Characterization of MM-derived exosomes and BMSCs}

To investigate the effect of MM cell-derived exosomes on the BMSC growth, the exosomes derived from patients with MM CD138 ${ }^{+}$myeloma cell and MM cell line RPMI8226 were isolated. Isolated exosomes were subsequently evaluated and confirmed by TEM (figure 1A), and the

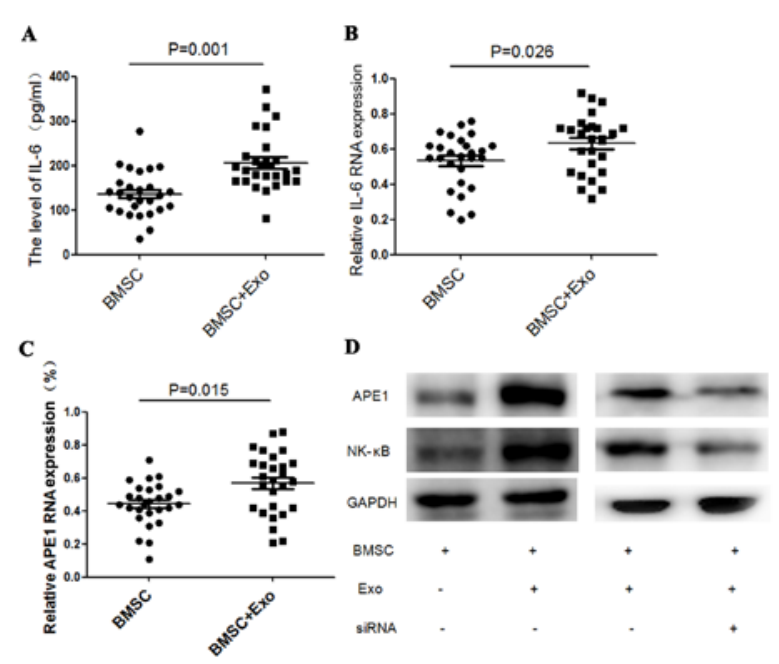

Figure 2 MM cell-derived exosomes induced IL- 6 secretion of BMSCs via the Ape1/NF-kB pathway. (A) The level of IL-6 in BMSC and culture media in RPMI-8226 cell-derived exosomes group $(200 \mu \mathrm{g} / \mathrm{mL})$ was significantly higher than the BMSC alone. $(B, C)$ The messenger RNA levels of IL- 6 and Ape1 in BMSC and RPMI-8226 cell-derived exosomes $(200 \mu \mathrm{g} / \mathrm{mL})$ coculture were higher than the BMSC alone. (D) RPMI-8226 cell-derived exosomes $(200 \mu \mathrm{g} / \mathrm{mL})$ inhibit the expression of Ape1 and NF-kB. The level of NF-kB was downregulated, followed by a decrease in Ape1 siRNA. BMSC, bone marrow stromal cell; Exo, exosome; IL-6, interleukin 6; MM, multiple myeloma;GAPDH,glyceraldehyde-3phosphate dehydrogenase; siRNA, small interfering RNA.

exosomes marker CD63 and Hsp70 from RPMI-8226 and MM patients-derived exosomes were analysed by western blot which were increased (figure 1B). The purity of BMSCs from patients with MM was evaluated by flow cytometry. The purity of all BMSCs was greater than 95\% (figure 1C). All the BMSCs were classical spindle cell under the microscope (figure 1D).

\section{MM cell-derived exosomes induced IL- 6 secretion of BMSCs via APE1/NF-kB pathway}

IL-6 plays an essential role in the proliferation, migration and drug resistance of MM cells. BMSCs were cultured with either RPMI-8226 cell-derived exosomes or PBS for 72 hours. IL- 6 analysis was performed using ELISA kit to detect the IL- 6 level in the cell culture media. Our results showed that RPMI-8226 cell-derived exosomes promoted IL-6 secretion by BMSCs after 72 hours of coculture (figure 2A). The mRNAexpressions of IL-6 and Ape1 were increased in RPMI-8226 cell-derived exosomes cocultured with the BMSC group (figure 2B,C). To better identify the influence of MM cell-derived exosomes on the secretion of IL-6, western blot was carried out to test the Ape1 and NF-kB levels, which were increased in RPMI-8226 cell-derived exosomes cocultured with BMSCs after 72 hours. With the downregulation of APE1 by small interfering RNA(siRNA), The level of NF-kB was decreased. Those results indicated that MM cell-derived exosomes induced IL-6 secretion of BMSCs via Ape1/ NF-kB (figure 2D). 
A

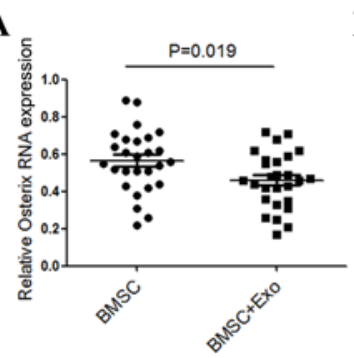

C

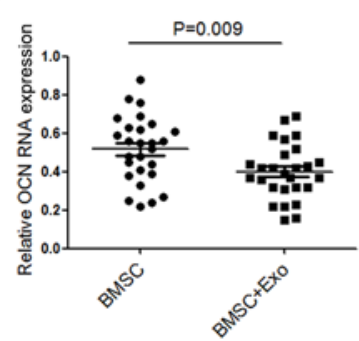

D
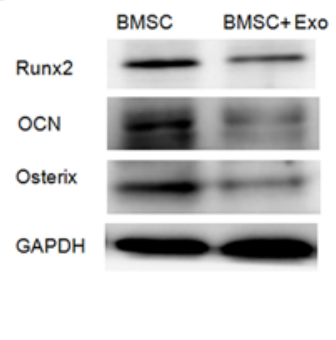

Figure 3 The level of Osterix, OCN and Runx2 in the BMSCs. (A-C) mRNA levels of Osterix, OCN and Runx2 in BMSC and RPMI8226 cell-derived exosomes $(200 \mu \mathrm{g} / \mathrm{mL})$ coculture were lower than the BMSC alone. (D) RPMI-8226 cell-derived exosomes $(200 \mu \mathrm{g} /$ $\mathrm{mL}$ ) inhibit the expression of osteoblast differentiation relative factors-Runx2, Osterix and OCN. BMSC, bone marrow stromal cell; Exo, exosome; mRNA, messenger RNA; OCN, osteocalcin, Runx2, runt-related gene 2,GAPDH, glyceraldehyde-3-phosphate dehydrogenase .

\section{MM cell-derived exosomes suppressed BMSC osteoblast differentiation and mineralization}

The mRNA expressions of OCN, Osterix and Runx 2 were decreased in RPMI-8226 cell-derived exosomes cocultured with the BMSC group. To better identify the influence of MM cell-derived exosomes on the osteoblastic differentiation, PCR and western blot were carried out to test the OCN, Osterix and Runx2 levels, which were decreased in RPMI-8226 cell-derived exosomes cocultured with BMSCs after 72 hours (figure 3A-D). After 21 days of culturing in the osteogenic induction media, the quantity and function of OBs were examined. Matrix formation and mineralization were observed through histochemistry. ALP and von Kossa staining positive are defined as the OBs. The quantity and function of OBs both continuously decreased with RPMI-8226 cell-derived exosomes (figure 4). The OB quantity cultured with RPMI-8226 cellderived exosomes was $1.63 \pm 0.38 \times 10^{5} / \mathrm{mL}$, while there was significant difference between the BMSC group and the BMSC + exosomesgroup $(p=0.001)$. The amount of mineralized nodules cultured with RPMI-8226 cell-derived exosomes (8.46 $\pm 1.59 /$ High power field, $\mathrm{HPF}$ ) was also significantly decreased in contrast to the BMSC group $(9.59 \pm 1.13 / \mathrm{HPF})(\mathrm{p}=0.004)$ (table 3$)$. According to these results, we found that suppress the differentiation (mineralization) of BMSCs into osteoblasts (figure 4).

\section{DISCUSSION}

Bone mesenchymal stem/stromal cells (BMSCs) define a population of progenitor cells capable of increasing at
A

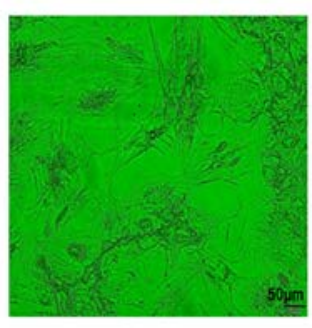

BMSC

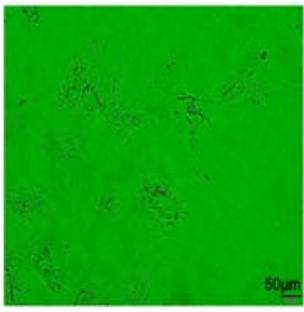

$\mathrm{BMSC}+\mathrm{ExO}$

B

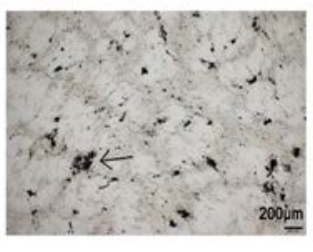

BMSC

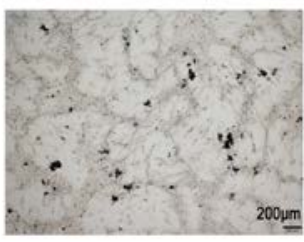

$\mathrm{BMSC}+\mathrm{E} \times \mathrm{O}$

C

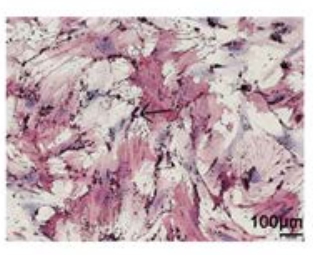

BMSC

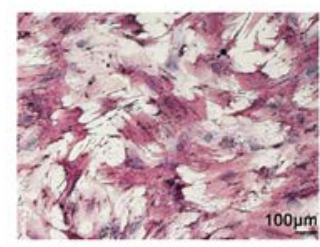

$\mathrm{BMSC}+\mathrm{E} \times 0$

Figure 4 MM cell-derived exosomes suppressed BMSC osteoblast formation and mineralization. (A) The quantity of $O B$ decreased in RPMI-8226 cell-derived exosomes group. (B) The amount of mineralized nodules (von Kossa staining) was decreased in RPMI-8226 cell-derived exosomes $(200 \mu \mathrm{g} / \mathrm{mL})+$ BMSC group compared with the BMSC group. (C) Alkaline phosphatase became weakly after the BMSCs were cultured for 3 weeks in RPMI-8226 cell-derived exosomes $(200 \mu \mathrm{g} / \mathrm{mL})$ compared with the BMSC group. BMSC, bone marrow stromal cell; MM, multiple myeloma.

least three mesodermal lineages in vitro: chondrocytes, osteoblasts and adipocytes. $^{25}$ The adhesion of MM cells to BMSCs can influence the activations of many pathways leading to upregulation of antiapoptotic proteins and cell cycle regulating cytokines. ${ }^{26}$ Exosomes, which are released from cells, play crucial roles in intercellular communication. Research revealed that exosomes are involved in some areas: as a disease biomarker, membrane vesicles as intermediary agent of immune responses and have effects on different cancers. ${ }^{27}$ MM cell-derived exosomes enhanced osteoclast activity and blocked osteoblast differentiation,

Table 3 Quantity and function of OBs cultured with RPMI-8226 cell-derived exosomes

\begin{tabular}{lll}
\hline & $\begin{array}{l}\text { Number of cells }\left(10^{9} /\right. \\
\mathrm{mL})\end{array}$ & $\begin{array}{l}\text { Number of } \\
\text { mineralized nodules } \\
\text { (per HPF) }\end{array}$ \\
\hline BMSC & $27.4 \pm 3.2$ & $9.59 \pm 1.13$ \\
BMSC + exosomes & $16.3 \pm 3.8^{*}$ & $8.46 \pm 1.59^{*}$ \\
\hline
\end{tabular}

*Indicates significant difference compared with the BMSC group.

BMSC, bone marrow stromal cell;HPF,High power field . 
leading to a reduction in Runx2, Osterix, and collagen 1A1 in osteoblasts in 5TGM1 murine model. ${ }^{28}$

Here, we pay attention to the effect of MM cell-derived exosomes in BMSCs from patients with MM. MM cellderived exosome is one major component of the tumor microenvironment. In order to observe the effect of MM cell-derived exosome, we added RPMI-8226 cellderived exosomes into BMSCs, and the IL-6 secretion was increased, and then the mRNA expressions of IL- 6 and APE1 were increased in MM cell (RPMI-8226)-derived exosomes cocultured with BMSCs. Western blot results indicated that the Ape1 and NF-kB levels were increased in MM cell (RPMI-8226)-derived exosomes cocultured with BMSCs after 72 hours. The level of NF-kB was downregulated, followed by a decrease in APE1. Those results indicated that MM cell-derived exosomes induced IL-6 secretion of BMSCs via the Ape1/NF-kB pathway. ${ }^{29}$

As the inhibition of BMSCs that differentiate into osteoblast is one important role in MBD, we next tried to detect the level of Runx2, OCN and Osterix, they are vital facts for the osteoblastic differentiation. The levels of Runx2, OCN and Osterix were decreased in BMSCs in MM cell (RPMI-8226)-derived exosome groups. The ALP and von Kossa staining decreased in MM cell (RPMI-8226)derived groups compared with the control groups. The IL-6 secretion of BMSCs is via NF-kB -dependent transcription. IL-6 is known to regulate MM cell proliferation and osteoclast differentiation. ${ }^{30}$ Our data showed that the IL-6 level increased in the $\mathrm{MM}$ exosome groups.

Runx2/Core-binding factor 1 (Cbfa1), a transcription factor which is essential for osteoblast differentiation and bone formation, ${ }^{31}$ directly regulates the expression of OCN. ${ }^{32}$ In Osterix-deficient mice, Runx2 is expressed in mesenchymal cells. However, Osterix is absent in Runx2deficient mice. ${ }^{33}$ These findings suggest that Osterix may function as downstream of Runx2 during osteoblast differentiation. Our results confirmed that MM exosome inhibited BMSC osteoblast differentiation by downregulating the expression of Runx2, Osterix and OCN.

Above all, we hypothesized that MM cell-derived exosomes might contribute to IL- 6 secretion and osteoblastic differentiation of BMSCs. The exosome may be a communicator in the cross-talk between MM and BMSCs. But how the exosomes enter and the effect mechanism on BMSCs from patients with MM need further study.

Contributors $\mathrm{ZL}, \mathrm{HL}$ and RF designed this research. ZL and YL carried out most of the experiments, analyzed the data, drew the figures and drafted this manuscript. JC and QS helped with the cell culture, western blot experiments, qRT-PCR and the FCM. JS helped check the manuscript and figures. All authors read and approved the final manuscript.

Funding The study was supported by the National Natural Science Foundation of China (grant no 81770110), the Tianjin Municipal Natural Science Foundation (grant no 15JCYBJC24300, 2018KJ043, 2018KJ045 and 18JCQNJC80400) and the Youth Incubation Fund of Tianjin Medical University General Hospital (ZYYFY 2016006). Tianjin Institute of Lung Cancer provided support in the lab.

Competing interests None declared.

Patient consent for publication Not required.

Ethics approval This study was approved by the Ethics Committee of Tianjin Medical University (IRB-2016-YX-081).

Provenance and peer review Not commissioned; externally peer reviewed.
Open access This is an open access article distributed in accordance with the Creative Commons Attribution Non Commercial (CC BY-NC 4.0) license, which permits others to distribute, remix, adapt, build upon this work noncommercially, and license their derivative works on different terms, provided the original work is properly cited, an indication of whether changes were made, and the use is non-commercial. See: http://creativecommons.org/ licenses/by-nc/4.0/.

\section{ORCID iD}

Zhaoyun Liu http://orcid.org/0000-0002-2730-1562

\section{REFERENCES}

1 Uchiyama H, Barut BA, Mohrbacher AF, et al. Adhesion of human myelomaderived cell lines to bone marrow stromal cells stimulates interleukin-6 secretion. Blood 1993;82:3712-20.

2 Gupta D, Treon SP, Shima Y, et al. Adherence of multiple myeloma cells to bone marrow stromal cells upregulates vascular endothelial growth factor secretion: therapeutic applications. Leukemia 2001;15:1950-61.

3 Tai YT, Li XF, Breitkreutz I, et al. Role of B-cell-activating factor in adhesion and growth of human multiple myeloma cells in the bone marrow microenvironment. Cancer Res 2006;66:6675-82.

4 Vallet S, Mukherjee S, Vaghela N, et al. Activin A promotes multiple myelomainduced osteolysis and is a promising target for myeloma bone disease. Proc Natl Acad Sci U SA 2010:107:5124-9.

5 Théry C. Exosomes: secreted vesicles and intercellular communications. F1000 Biol Rep 2011;3:15

6 Peinado H, Lavotshkin S, Lyden D. The secreted factors responsible for premetastatic niche formation: old sayings and new thoughts. Semin Cancer Biol 2011;21:139-46.

7 Peinado H, Alečković M, Lavotshkin S, et al. Melanoma exosomes educate bone marrow progenitor cells toward a pro-metastatic phenotype through MET. Nat Med 2012;18:883-91.

8 Zhang HG, Grizzle WE. Exosomes: a novel pathway of local and distant intercellular communication that facilitates the growth and metastasis of neoplastic lesions. Am J Pathol 2014;184:28-41.

9 Kharaziha P, Ceder S, Li Q, et al. Tumor cell-derived exosomes: a message in a bottle. Biochim Biophys Acta 1826;2012:103-11.

10 Raimondi L, De Luca A, Amodio N, et al. Involvement of multiple myeloma cellderived exosomes in osteoclast differentiation. Oncotarget 2015:6:13772-89.

11 Wang J, Hendrix A, Hernot $S$, et al. Bone marrow stromal cell-derived exosomes as communicators in drug resistance in multiple myeloma cells. Blood 2014; $124: 555-66$

12 Xu S, Cecilia Santini G, De Veirman K, et al. Upregulation of miR-135b is involved in the impaired osteogenic differentiation of mesenchymal stem cells derived from multiple myeloma patients. PLoS One 2013;8:e79752.

13 Arendt BK, Walters DK, Wu X, et al. Multiple myeloma dell-derived microvesicles are enriched in CD147 expression and enhance tumor cell proliferation. Oncotarget 2014;5:5686-99.

14 Sun L, Wang HX, Zhu XJ, et al. Serum deprivation elevates the levels of microvesicles with different size distributions and selectively enriched proteins in human myeloma cells in vitro. Acta Pharmacol Sin 2014;35:381-93.

15 Fu R, Liu H, Zhao S, et al. Osteoblast inhibition by chemokine cytokine ligand3 in myeloma-induced bone disease. Cancer Cell Int 2014;14:132.

16 Liu H, Peng F, Liu Z, et al. CYR61/CCN1 stimulates proliferation and differentiation of osteoblasts in vitro and contributes to bone remodeling in vivo in myeloma bone disease. Int J Oncol 2017;50:631-9.

17 Jiang F, Liu H, Liu Z, et al. High serum levels of complements C3 and C4 as novel markers for myeloma bone disease. Ann Hematol 2017:96:331-3.

18 Fu R, Peng F, Liu H, et al. Clinical significance of osteoblast precursors and osteoclast precursors in earlier diagnosis and monitoring of myeloma bone disease. Ann Hematol 2016;95:1099-106.

19 Li X, Wang S, Zhu R, et al. Lung tumor exosomes induce a pro-inflammatory phenotype in mesenchymal stem cells via NFKB-TLR signaling pathway. J Hematol Oncol 2016:9:42.

20 Muller L, Hong CS, Stolz DB, et al. Isolation of biologically-active exosomes from human plasma. J Immunol Methods 2014;411:55-65.

21 Geyh S, Oz S, Cadeddu RP, et al. Insufficient stromal support in MDS results from molecular and functional deficits of mesenchymal stromal cells. Leukemia 2013;27:1841-51

22 Liu Z, Chen J, Wang H, et al. Chidamide shows synergistic cytotoxicity with cytarabine via inducing $\mathrm{G} 0 / \mathrm{G} 1$ arrest and apoptosis in myelodysplastic syndromes. Am J Trans/ Res 2017;9:5631-42. 
23 Roccaro AM, Sacco A, Maiso P, et al. BM mesenchymal stromal cellderived exosomes facilitate multiple myeloma progression. J Clin Invest 2013;123:1542-55.

24 Kwon JS, Kim SW, Kwon DY, et al. In vivo osteogenic differentiation of human turbinate mesenchymal stem cells in an injectable in situ-forming hydrogel. Biomaterials 2014;35:5337-46.

25 Sheng G. The developmental basis of mesenchymal stem/stromal cells (MSCS). BMC Dev Biol 2015;15:44

26 Hideshima T, Bergsagel PL, Kuehl WM, et al. Advances in biology of multiple myeloma: clinical applications. Blood 2004;104:607-18.

27 Lou G, Song X, Yang F, et al. Exosomes derived from miR-122-modified adipose tissue-derived MSCs increase chemosensitivity of hepatocellular carcinoma. J Hematol Oncol 2015;8:122.

28 Faict S, Muller J, De Veirman K, et al. Exosomes play a role in multiple myeloma bone disease and tumor development by targeting osteoclasts and osteoblasts. Blood Cancer J 2018;8:105.
29 Xie JY, Li MX, Xiang DB, et al. Elevated expression of APE1/Ref-1 and its regulation on IL-6 and IL-8 in bone marrow stromal cells of multiple myeloma. Clin Lymphoma Myeloma Leuk 2010;10:385-93.

30 Löwik CW, van der Pluijm G, Bloys $\mathrm{H}$, et al. Parathyroid hormone (PTH) and PTH-like protein (PLP) stimulate interleukin-6 production by osteogenic cells: a possible role of interleukin-6 in osteoclastogenesis. Biochem Biophys Res Commun 1989;162:1546-52.

31 Komori T, Yagi H, Nomura S, et al. Targeted disruption of Cbfa1 results in a complete lack of bone formation owing to maturational arrest of osteoblasts. Cell 1997;89:755-64.

32 Ducy P, Zhang R, Geoffroy V, et al. Osf2/Cbfa1: a transcriptional activator of osteoblast differentiation. Cell 1997;89:747-54.

33 Nakashima K, Zhou X, Kunkel G, et al. The novel zinc finger-containing transcription factor osterix is required for osteoblast differentiation and bone formation. Cell 2002;108:17-29. 